\title{
Reflective Leadership in EFL
}

\author{
Suleyman Davut Göker \\ Department of English Translation and Interpretation, Faculty of Humanities, Girne American University, \\ North Cyprus via Mersin 10, 98000 Turkey \\ Email: gokersd@yahoo.com
}

\begin{abstract}
There seems to be a large discrepancy between leading and learning roles of EFL (English as a foreign language) teacher, learner and principal, which often makes EFL schools fail to build a coherent, collaborative system that supports powerful, equitable learning for all learners. Based on the discrepancy above, in this article, I introduce a reflective leadership framework (RLF) for EFL learners, teachers, and principals, which offers a vision of desirable practice for these three stakeholders with particular roles rather than a set of recipes or a change theory. Reflective leadership is used to describe the concept that learners, teachers and principals should be leaders and learners. I argue that with this reflective leadership type, in which all individuals are empowered to lead for learning, EFL schools could be more effective due to their unique contexts. In this leadership framework, 3 distinct concepts-learning, teaching, and leading-are mutually supportive for more powerful connections between leading and learning. This leadership type particularly offers a theoretically grounded framework for EFL schools, which desire to initiate a communicative curriculum with new leadership roles for students, teachers, and principals by drawing on the following bodies of literature: leading for learning, school-based management, creating a reflective learning community.
\end{abstract}

Index Terms—reflective leadership, reflective learning community, leading for learning

\section{INTRODUCTION}

Even though effectiveness of a leader is mostly measured in quantitative outcomes, it is our ability to reflect on, and optimize our relationships that help us achieve these goals. In other words, our accomplishments are a reflection of what our relationships have allowed us to achieve in connection with others, guiding and mentoring them as a natural outgrowth of good relationships. Therefore, leadership takes place in the context of relationships, and quality relationships are crucial to good outcomes.

Considering the relationships of teachers, learners, and principals in an EFL school, and opportunities created along pathways to learning, there continues to be a communication breakdown among the leadership tasks and skills assigned to learners, teachers and principals and this role conflict creates a chaotic atmosphere together with challenges associated with the adoption of communicative language teaching in those schools, which employ learner-based task and activities which feature learner leadership and autonomous learning. However, Knapp, Copland, and Talbert (2003) argue that leading for learning involves finding and creating strategic opportunities and relationships along pathways to learning, that have the greatest influence on the interactions of students, teachers, and content. Learner's opportunities for learning reside in these interactions, and learning depends on how teachers implement curriculum, design communicative tasks, and engage learners in these tasks, as well as how learners approach their teachers, other learners, and their work. Through similar types of opportunities, principals also look at the learning environment they have created and learn to establish and support teachers' and learners' learning. Each learning acts as context for the other two. Teachers and principals, like students, develop and change from the inside out - through individual practice and reflection - and from the outside in - through contact with the experiences and theories of others. The purpose of this article is to frame the concept of reflective leadership defining the leadership roles for teachers, students, and principals under a school-based reflective management model (SBRM) developed by Göker (2006a). It further identifies potential outcomes of demonstrating these reflective leadership behaviors in a synchronized way.

\section{Reflection and Reflective Teaching and Learning}

Reflective thinking, with its roots in the work of many educational theorists and practitioners, is not an innovation in teaching and learning. It has been around for more than 50 years. For example, scholars like Richards, Lockhart, Ramirez, and Wallace have carried out studies to help EFL teachers and learners to learn in a reflective environment. The concept of reflection is already installed in a range of learning theories and therefore has various meanings. Within communicative English language teaching (ELT) methodology, reflection is predominantly conceptualized as process of critical analysis through which learners, teachers and principals extract knowledge from their experience. For the purposes of this article, growth through reflection occurs when members of a group subject their personal beliefs about teaching and learning to a critical analysis, and thus take more responsibility for their actions (Korthagen, 1993). This critical analysis puts classroom experiences into context for teachers, learners, and principals, thus providing them with a much richer understanding of what takes place in the classroom and in their own construction of reality. Critical 
analysis of teaching in context is one of the more effective ways to encourage developmentally and culturally appropriate reflective practice (Milner, 2003).

In the reflective learning community model, sustainable change, resulting in improved teaching and learning, is best generated when educators engage in collective learning processes characterized by reflective analysis of current conditions, experimentation with new possibilities for practice, and ongoing assessment of the relationship between practice and the effects of practice (Kofman \& Senge, 1993; Sergiovanni, 1996). A combination of a self-reflective culture and leadership in schools is essential to create a learning community. Several aspects of a learning culture have been identified: a spirit of trust and mutual respect in collective processes, common understandings about organizational activities and initiatives, shared purposes and goals, and an ongoing search for new and better ways of working (Hajnal, Walker, \& Sackney, 1998).

I propose that a self-reflective culture in EFL schools as learning communities could, and should, be developed by the leadership strength of these three stakeholders: the learners, teachers, and principals. In addition, all changes involve reflective learning and growth for learners, teachers, and principals simultaneously to create a communicative and reflective learning community.

Why is Reflective Leadership Needed in the EFL Contexts?

The concept "autonomous learning" occurred in the early 1960's together with debates about the development of lifelong learning skills and independent thinking and many scholars gave their interpretation towards this concept, such as "the ability to take charge of one's own learning"(Holec, 1981); "situation in which the learner is totally responsible for all of the decisions concerned with his/her learning and the implementation of those decisions"(Dickinson, 1987); "a recognition of the rights of learners within educational systems"(Benson, 1997) and so on (Jingnan, 2011). Over the past 25 years, learner autonomy has been a popular focus for discussion and increasingly influential in foreign language education together with the development of reflective teaching.

The 1970s became an era of change and innovation in language teaching and learning processes. Many of the innovative methods of the 1970s had a very short shelf life because they were linked to highly specific claims and to prescribed practices (Richards \& Rodgers, 2001). Good teaching was seen as correct and proper use of of the method and its prescribed principles and techniques. Likewise, learners were often viewed as passive recipients who should submit themselves to a regime of exercises and activities. What is called the "post methods" era thus lead to a focus on the processes of learning and teaching rather than ascribing a central role to methods as the key to successful teaching and attention shifted to how teachers could develop and explore their own practice through reflective teaching and action research (Richards \& Lockhart, 1994). In order to foster this kind of reflective teaching, learners also had to take responsibility for their own learning, such as planning learning tasks, selecting learning method, and evaluating learning process. However, creating such a reflective learning community requires a combination of a self-reflective culture and leadership in schools where principals should also be responsible for common understandings about organizational activities and initiatives, shared purposes and goals. From this stand point of view, the thinking was that teacher reflection and research could lead to the revitalization of teaching and learning from the inside, rather than trying to make teachers, principals, and learners conform to an external model. By consistently acting as models or mentors, teachers and school leaders reinforce the core values and mission of the school (Deal \& Peterson, 1994), and learners act respectively.

In this sense, the TEFL context may be viewed as the pioneer of change and innovation in teaching methodology as compared to other subject areas due to the following reasons. It, first of all, has a wide range of teaching materials including online teaching tasks, handouts, activities, thousands of web pages for EFL teachers and learners as most textbooks, published in Britain and America, are designed with an eye to sales and ignore the the cultural values of the students' countries. All language curricula should be developed based on a needs and goal analysis of each EFL school, which make EFL teaching different from other subject area teaching. The ongoing practice of individualized instruction in EFL, such as one-to-one teaching, home study, self-access learning, self-directed learning, and the movement toward learner autonomy, also values the needs and active involvement of the language learner.

There have also been many changes in the contexts and resources for EFL learning, as learning is not confined to the classroom setting. EFL teaching and learning seems to access more resources (e.g., computer-assisted language learning or audio-visual laboratories, TV, tapes) than most other subject areas. Videos, computers, and the Internet are accessible to almost all teachers and learners, and in some schools the language laboratory has been turned into a multimedia center that supports online learning. After finishing each task or activity, learners should reflect the work they did and write a few words to remain for themselves of their performance they would consider in future self-access work. Different types of syllabi such as grammatical, lexical, grammatical-lexical, situational, topic-based, notional, functional-notional, mixed or multistrand, procedural, or process are implemented in each EFL school (Richards \& Rodgers, 2001). In addition, different types of tests depending on the learner needs in each school are administered (proficiency, achievement, placement, or diagnostic).

Given these unique contextual characteristics, a diversified EFL school curriculum can be regarded as a network of interacting systems, which requires effective reflective leadership skills of teachers, learners, and principals collectively. Because such a complex and interacting system does not lend itself to effective leadership of any of these stakeholders only (Göker, 2007). Rather, this curriculum implies a reflective learning community where leaders engage in collective 
learning processes to diagnose problems, adapt materials, and design original learning activities. It is evident that the EFL context is substantially different from contexts for other subject area teaching.

\section{Building Reflective Leadership in an EFL School}

Educational systems throughout the world have recently embraced (at least in principle) an evolution from largely centralized structures to more decentralized ones. The rationale for decentralized schooling, and particularly schoolbased management (SBM), argues that the school is the primary unit of change; those who work directly with students have the most informed and credible opinions about educational arrangements that will be most beneficial to their students. Leaders, at the center of changes, should determine their own readiness for change before undertaking the complex process of changing schools and they can discover their change readiness by becoming reflective practitioners who know themselves and engage in professional learning (Zimmerman, 2011). A substantial research literature has demonstrated that SBM can be used effectively to improve student and teacher performance (Göker, 2005, 2006a; Brown, 1990; Ceperley 1991; Conley \& Bacharach, 1990). Based on the research findings about SBM, reflective teaching and learning, and the uniqueness of EFL contexts, I argue that a reflective learning community can be created for principals, teachers, and students to implement a quality EFL curriculum as it results from active ongoing efforts of teachers, principals, and students and a shared commitment to SBRM principles, role changes, and the selection of appropriate measures to bring these about. (Göker, 2005, 2006a).

To develop a reflective leadership framework (RLF), there must be some principles to create a learning community which offers leaders reflective tools guiding self-assesment and planning to discovering more powerful connections between leading and learning, the RLF comprises these principles:

1. Powerful and equitable student learning is the central goal of leadership.

2. EFL schools are reflective learning communities where action research is used under a school-based organizational structure in which all individuals are empowered to lead, as well as contribute to, particular strategies that focus on learning.

3. EFL schools develop a sense of community with shared vision and goals and the primary focus in these schools is communicative competence.

4. Reflective teaching is an essential part methodology.

5. Learners, teachers, and principals determine their own readiness for change.

6. EFL schools recruit quality teachers (Farrell, 2001; Göker, 2006a, 2007; Richards \& Rodgers, 2001).

7. EFL schools engage in continuous restless self-examination and have the policy of openness about performance data within the school.

8. Teachers convey and reinforce high expectations and learners are encouraged to use their creative imagination and powers of problem solving with communicative tasks and activities.

9. Positive reinforcement is a very effective system for the teacher and the students.

10. Accountability: As accountability systems evolve, they are likely to have considerably stronger impacts if they move in the direction of more precise incentives for individual schools. Analysis of state achievement growth as measured by the National Assessment of Educational progress shows that accountability systems introduced during the 1990s had a clear positive impact on student achievement (Raymond \& Hanushek, 2003; National Assessment of Educational Progress, 2004).

11. Well-established mechanisms are used in EFL schools.for monitoring the progress of learners, classes, the school as a whole.

12. Students are active and they have responsibility for their own learning, and thus student self-esteem is raised (Crookes \& Schmidt, 1991; Young, 1991).

13. There are strong home-school partnerships in EFL schools.

14. Language learning is not confined to the classroom in EFL schools in terms context and resources which provides access to more authentic input and learning processes.

\section{ROLES İN THE REFLECTIVE LEADERSHIP FRAMEWORK (RLF)}

A growing body of implementation research on SBM reports that the roles of all educational stakeholderssuperintendents, other central office personnel, board members, principals, teachers, other school staff, and often parents, community members, and students - are profoundly affected. It is also reported that SBM and shared decision making strategies directly challenge and tend to change the complex and well-entrenched patterns of institutional and individual behaviors that have remained untouched by top-down reforms (Ceperley 1991; Hord, 1992; Snipes, Doolittle \& Herlihy, 2002). What happens when an EFL school under SBM desires to initiate changes intended to reflect a more communicative approach to English language learning with the leadership roles under the the RLF?

Since such an EFL school under SBM has complex and interacting system, it does not lend itself to effective leadership of any of these stakeholders only. Therefore, if an EFL school desires to adopt reform strategies to create a reflective learning community, these new expectations involve role changes for teachers, students, and principals because they become participants in whole-school change and are asked to engage in reflective practice. I focus on reflective leadership role changes for only principals, teachers, and students. Leadership, then, not only refers to administration; teachers and students also take action on school-wide issues and are therefore modeling reflective 
leadership. Central to these assertions about reflective leading for learning is the notion that reflective leaders not only set the stage for learning but also take concrete steps along pathways to learning. In this sense, the reflective leadership framework (RLF) comprises new leadership roles for principals, teachers, and learners.

\section{Principal Roles in the Reflective Leadership Framework (RLF)}

Recent research suggests that regular reflection increases leaders' learning and may make them more effective (Densten and Gray, 2001; Stoeckel and Davies, 2007). In the constantly changing learning environment of today's EFL schools, the practice of reflection may be of great value to new generations of leaders. Today's schools require a new kind of principal, one whose main responsibility involves leadership that focuses on strengthening teaching and leading for learning (Elmore, 2002; Fink \& Resnick, 2001; Hess, 2003; Southern Regional Education Board, 2003; Thomas B. Fordham Institute \& Broad Foundation, 2003).

Leading for learning involves developing clarity and coherence in the improvement agenda (Knapp et al., 2003). In this sense, principals connect activities along multiple pathways to one another and to student, reflective, and sytem learning. Principals have the challenge and obligation to develop an environment that not only attracts the best teachers available, but one that also retains and develops them throughout their career (Watkins, 2005).

I propose that under the RLF, it is the role of the principal that is subject to the greatest degree of change. The principal:

1. Is not a boss but a head learner;

2. Not only sets the stage for learning but also takes concrete steps along pathways to learning;

3. Serves as leader for learner learning;

4. Learns to establish and support teachers' and students' reflective learning through creating coherence;

5. Works collegially with staff, sharing authority with them;

6. Builds professional communities that value learning, acts strategically and shares leadership;

7. Engages external environments that matter for learning;

8. Serves as a curriculum developer, supervisor, and instructional manager;

9. Plans and coordinates the assessment policy and practices;

10. Leads other teachers in improving learning strategies through staff development, collaborative lesson preparation, and selection and development of learning and teaching resources;

11. Promotes a professional exchange culture within the school and establishes links with other schools for sharing of experiences in learning, teaching, and curriculum development;

12. Envisions himself or herself as the chief reflective practitioner;

13. Articulates his or her personal values and beliefs about teaching and learning;

14. Facilitates active learning, critical thinking, and problem-solving skills;

15. Is a developer of reflective learning for learners and teachers;

16. Uses a range of self, peer, and student monitoring and evaluating techniques. (Göker, 2006a, p.191)

Leading for learning means creating powerful and equitable learning opportunities for students, professionals, and the system, and motivating participants to take advantage of these opportunities (Knapp et al., Cop., 2003). Leaders can accomplish this by committing themselves to the following areas of action: Establishing a focus on learning, building professional communities that value learning, engaging external environments that matter for learning, acting strategically, and creating coherence (Knapp et al., 2003; Ouchi, 2003). The vision offered focuses on providing all learners, regardless of the difficulties they face, the means to master challenging skills and to develop habits of mind for further learning, as well as independent learning.

The question is, "How does inquiry into performance focus on what learners and teachers are learning and how do EFL school principals as leaders influence learning through these roles, and what reflective ideas and tools are needed under the RLF? To pursue this end, EFL school principals engage three learning agendas: student learning, reflective learning, and system learning (Cohen \& Hill, 2001; McLaughlin \& Talbert, 2001).

Student learning. Students' opportunities for learning reside in the interactions among learners, teachers, and content. Learning - the outcomes of all these interactions - depends on how teachers implement curriculum, design academic tasks, and engage students in these tasks, as well as how learners approach their teachers, each other, and their work (Knapp et al., 2003). EFL school principals establish a focus on learning and students by consistently communicating that student learning is the shared mission of students, teachers, principals, and the community. If language learning is to be successful, the students' needs, rather than the grammar or functions of English, must form the core of the curriculum and the instruction. The focus must be on the skills of creative and critical thinking, information processing, reasoning, inquiry, and evaluation (Butterworth \& O'Connor, 2005; Göker, 2005, 2006a).

Reflective learning. "Let's try it out and see how it works" is an active learner's phrase; "Let's think it through first" is the reflective learner's response. Teachers' learning includes the knowledge, skills, and perspectives they acquire while preparing for and renewing their practice. Opportunities for effective professional development include those that come from interacting with other professionals who offer ideas, critique, inspiration, and moral support in the renewal process (Farrell, 2001).

Given time to reflect, most principals want to provide more powerful and equitable learning opportunities. However, principals' abilities depend on their understanding of existing and potential connections between leading and learning in 
their particular setting. As part of professional development, principals can use reflective tools including strengthening electronic portfolios with reflective writing, optimizing video as a self-assessment tool, accessing relevant resources on the Internet, tapping into online peer mentoring, and encouraging reflection through learning communities.

EFL school principals can learn to establish and support teachers' and students' reflective learning through creating coherence (National Association of Elementary School Principals, 2002), building professional communities that value learning, acting strategically and sharing leadership, and engaging external environments that matter for learning.

System learning. Opportunities for system learning arise through strategic planning endeavors; evaluation of policies, programs, and resource use; action research focused on system-wide issues; and application of indicators to measure progress toward defined goals (Knapp et al., 2003). Through inquiry into how a school functions and performs, principals can support system learning (Snyder, 2002). This may include insight into the functioning of the SBRM system, as a whole, to develop and evaluate new policies, practices, and structures that enhance its performance.

\section{Teacher Roles in the Reflective Leadership Framework (RLF)}

Learning from examining one's own teaching, from carrying out classroom research, from creating teaching portfolios, from interacting with colleagues through critical friendships, mentoring and participating in teacher networks, are all regarded as ways in which teachers can acquire new skills and knowledge (Bartlett, 1990; Jacobs and Farrell, 2001; Pickering, 2003). Bartlett (1990) points out that becoming a reflective teacher involves moving beyond a primary concern with instructional techniques and "how to" questions and asking "what" and "why" questions that regard instructions and managerial techniques not as ends in themselves, but as part of broader educational purposes.

Through guided reflection on field experiences, self-analysis and evaluation, professional development can be assured. Teachers must reflect, analyze, and adjust or change their practice whenever it is necessary; otherwise, thinking would actually become a waste of time. What really will make the difference when reflective/action research practice is performed is the fact that the results are empowering in helping ESL/EFL teachers become better teachers (Pacheco, 2005). Many different approaches can be employed if an EFL teacher wishes to become a critically reflective, including peer observation, written accounts of experiences, self-reports, teachers' diaries, recording lessons, reflective inquiry groups, and collaborative action research.

Reflective teaching suggests that experience in teaching alone is not enough for professional growth, but that experience along with reflection can be an effective path for EFL teacher's professional development. A substantial research literature also demonstrates that peer coaching is one of the most effective means to improve student and teacher performance and to bridge the gap between theory and practice. It helps teachers to deepen collegiality, increase professional dialogue, and gives them a shared vocabulary to talk about their craft. In peer coaching, the key to teacher satisfaction and learning, and to program success is teacher ownership of the process (Göker, 2006b; Seferoğlu,2001; Gottesman, 2000).

Developing a reflective teaching philosophy can help clarify decisions about choice of classroom activities, materials, and teacher evaluation. The following statements describe the reflective EFL teaching philosophy and teacher roles supporting the RFL (Adler \& Reed, 2000; Farrell, 2001; Göker, 2005, 2006a):

1. EFL classroom becomes a kind of laboratory where the teacher can relate teaching theory to teaching practice.

2. EFL schools develop clarity and coherence in the improvement agenda.

3. Teachers are learners, reflective practitioners, critical enquirers, and context-sensitive professionals.

4. Teachers take concrete steps along pathways to learning, and setting the stage for learning.

5. Language learning is a gradual process that involves trial and error.

6. Teachers become a critically reflective.

7. Teachers serve as facilitators of learning, rather than as presenters of information.

8. Teachers learn how to use reflective tools to encourage reflection.

9. There is a consistent focus throughout on learning English to develop practical and functional skills, rather than as an end in itself.

10. Learners are engaged in practical tasks that relate to real world uses of English.

11. There is an appropriate balance between accuracy-focused and fluency-focused activities.

12. Realistic and communicative uses of language are given priority.

13. Maximum use is made of pair and group activities where students complete tasks collaboratively.

14. Assessment procedures reflect and support a communicative and skill-based orientation to teaching and learning.

15. Learners develop the ability to monitor their own learning process and ways of setting personal goals for language development.

16. Learners have an awareness of the learning process and their own learning styles, strengths, and weaknesses.

17. Teachers expand their repertoire of routines, skills, and strategies to try out new strategies in the classroom.

18. Teachers monitor themselves and get feedback from others on their practice.

19. Teachers develop an understanding of different styles of teaching and determine learners' perceptions of classroom activities.

20. Teachers navigate the complex interplay among the values and cultural norms of schools, students, and teachers. 
Due to the fact teacher collaboration is essential, I argue that, under the RFL, teachers will be asked to become key partners in schools with the previously described roles and to assume leadership roles in staff development, mentoring, and curriculum development.

\section{Learner Roles in the Reflective Leadership Framework (RLF)}

Reflective learners evaluate their strengths and weaknesses, setting themselves realistic goals with criteria for success. In language learning process, this means understanding how to assess themselves on their performance in four skills; writing, reading, listening, and speaking. Reflective learners self-improve and develop their personal effectiveness, and invite feedback from their peers and teachers. They also deal positively with praise, setbacks and criticism.

Realistic learner beliefs and learner autonomy will be created, and thus the learners' self-confidence and motivation will be increased if learners are to become active participants in decision-making regarding their own learning, then it is essential that they be able to state their own learning goals (Adler \& Reed, 2000; Farrell, 2001). Reflective learners are said to demonstrate self-awareness and motivation, awareness of the process of learning, and independence. Learners need to be exposed to situations that require them to lead, in order to develop individual skills that will enable them to be successful group and community leaders. Effective student leaders step out and risk failure because they know failure and disappointment are a normal part of growth. Current communicative language teaching and learner-centered courses will require the following new roles for learners, in addition to the ones indicated in the RLF philosophy:

1. develops habits of mind for further learning as well as independent learning;

2. manager of his or her own learning;

3. creative and critical thinker, and information processor;

4. independent learner;

5. has more awareness about his or her self-regulated learning strategies;

6. needs analyst;

7. collaborator and team member;

8. peer tutor;

9. meaning negotiator; and

10. reflective learner.

Learners with these roles should not be isolated from operational and policy decisions in a reflective learning community, because they will influence the teaching philosophy and principles by giving advice and input.

\section{PRedictable Gains AND OUTCOMES UNDER RLF}

Through creating a learning environment where teachers, learners, and principals demonstrate reflective leadership, there can be significant outcomes to be gained in EFL schools.

1. Involvement in reflective-based managerial activities will contribute to the development of educators' perceptions of the nature and quality of the total school climate.

2. In EFL schools sustainable change, resulting in improved teaching and learning, is best generated.

3. EFL schools will be reflective learning communities. Community members will be critical friends and confidentiality and trust built up in the community will increase job satisfaction.

4. EFL schools will be able to cope with global developments, contribute to the personal growth of students, and build a competent workforce to sustain the social, economic, and cultural development of EFL context.

5. Accountability systems to be introduced at EFL schools will a clear positive impact on student achievement.

6. EFL learners will be managers of their own learning.

7. Materials development and adaptation will be conducted within the school. EFL teachers will be able to develop tasks and activities instead of teaching from textbooks imposed on them.

8. EFL school principals, as leaders, will directly influence learning.

9. Each EFL school has a unique context and a diversified and flexible language curriculum can be created within the school.

10. EFL teachers and principals will be in charge of curriculum development and evaluation where teaching, learning, and leading will be integrated.

11. Teaching for testing will end as an environment is created in which teaching and testing are integrated. Testing offices can be converted to databanks where all evaluation procedures will take place and can be accessible to everybody.

12. EFL departments within universities can have their own curriculum, instead of imitating those of other universities. Some students may enter an English-language university lacking a working knowledge of English. Universities assist their students to develop proficiency in the language of instruction for them to achieve and complete their own graduation outcomes through English support programs intended to provide an intensive instruction in literacy as a foundation for further study in all content areas.

13. Students will be involved in curriculum evaluation and the curriculum will be made relevant for them.

14. Learner input in deciding what to learn and how to acquire their learning will be high, as they will not be told to do what is required by the school.

15. Students will have more awareness about their self-regulated learning strategies. 


\section{CONCLUSIONS}

EFL schools, as reflective learning communities, need to develop a policy and manage external pressures and internal pressures that push schools and the people in them to develop and change in relation to their resources; they need to ensure that they and the people in them can change and develop an integrative concept and practice of reflection. Due to these pressures, changes in EFL teaching have been happening at ever-faster rates with ever-increasing complexity. Innovations are offered for adoption; some are accepted and others are not. Curriculum reforms have been handed down from education ministries, instructional technology innovations are being applied at all levels, research from many disciplines is informing classroom-based innovations, and action research is becoming more commonplace, thus resulting transformations of teachers at the local level. All these are linked to a paradigm shift resulting in a greater focus on reflective practice, rather than on methods and methodology. Without effective leading for learning, all these forces could merely create fragmented and short-lived initiatives in EFL teaching.

To make leading for learning more concrete, there are two paths to follow. First, to illustrate a reflective practice, a strong and reflective learning-focused community should be created which offers professional support, renewed commitment, a setting for managing conflicts, and helps with problems of practice. Second, I outline what I propose are the key elements of reflective learning; elements that, taken together, provide a reflective leadership framework within which to develop both an expansive concept of reflection and a range of integrative individual and collective reflective practices is essential. It is therefore hoped that, via such a reflective learning environment, greater success can be achieved in the design and implementation of ELT innovations.

\section{REFERENCES}

[1] Adler, J., \& Reed, Y. (2000). Researching teachers' 'take-up' from a formal in-service professional development programme. Journal of Education, 25, 192-226.

[2] Bartlett, Leo. (1990). Teacher development through reflective teaching. In J.C. Richards and D. Nunan (Eds), Second Language Teacher Education (pp. 2002-214). New York: Cambridge University Press.

[3] Benson, P. (1997). The Philosophy and Politics of Learner Autonomy. In P. Bensyon \& P. Voller (Eds.). Autonomy and Independence in Language Learning, pp.29-30. London:Longman.

[4] Brown, D. J. (1990). Decentralization and school based management. London: Falmer Press.

[5] Butterworth, M., \& O’Connor, M. (2005). Thinking through English. New York: Chris Kington.

[6] Ceperley, P. (1991). Site-based decision-making: Policymakers can support it or undermine it. The Link, 10(21), 7-9.

[7] Cohen, D. K., \& Hill, H. C. (2000). Instructional policy and classroom performance: The mathematics reform in California. Teachers College Record, 102, 294-343.

[8] Conley, S. C., \& Bacharach, S. B. (1990). From school-site management to participatory school-site management. Phi Delta Kappan, 71, 539-544.

[9] Crookes, G., \& Schmidt R. (1991). Motivation: Reopening the research agenda. Language Learning, 41, 469-512.

[10] Deal, T., \& Peterson, K. (1994). The leadership paradox: Balancing logic and artistry in schools. San Francisco: Jossey-Bass.

[11] Densten, I. L., and Gray, J. H. (2001). Leadership development and reflection: What is the connection? International Journal of Educational Management, 15(3), 119-124.

[12] Dickinson, L. (1987). Self-instruction in language Learning, pp. 9-12. Cambridge: Cambridge University Press.

[13] Elmore, R. (2002). Bridging the gap between standards and achievement: The imperative for professional development in education. Washington, DC: Shanker Institute.

[14] Farrell, T. (2001). Tailoring reflection to individual needs: A TESOL case study. Journal of Education for Teaching, 27, 23-38.

[15] Fink, E., \& Resnick, L. (2001). Developing principals as instructional leaders. Phi Delta Kappan, 82, 598-606.

[16] Göker, Süleyman D. (2005). A School-based management and supervision model (SBMS) in EFL Schools. The Internet TESL Journal, January 2005.

[17] Göker, Süleyman D. (2006a). Leading for learning: Reflective management in EFL. Theory into Practice. Spring 2006, Volume. 45, No. 2, pp. 187-196.

[18] Göker, Süleyman D. (2006b). Impact of peer coaching on self-efficacy and instructional skills in TEFL teacher education". System, An International Journal of Educational Technology and Applied Linguistics. 2006. 34/2 pp. 239-254.

[19] Göker, Süleyman D. (2007). Supervision without outside 'Super' visor in ELT (English Language Teaching). GAU Journal, Social and Applied Sciences. Fall 2007/3.

[20] Gottesman, B. (2000). Peer Coaching for Educators, Lanham, MD: Scarecrow Press.

[21] Hajnal, V., Walker, K., \& Sackney, L. (1998). Leadership, organizational learning and selected factors relating to the institutionalization of school improvement initiatives. The Alberta Journal of Educational Research, 44(1), 70-90.

[22] Hess, F. (2003). A license to lead? A new leadership agenda for America's schools. Washington, DC: Progressive Policy Institute, 21st Century School Project.

[23] Holec, H. (1981). Autonomy and Foreign Language Learning, pp. 2-5. Oxford: Pergamon Press.

[24] Hord, S. M. (Ed.). (1992). The new alliance of superintendents and principals: Applying the research to site-based decision making. Issues About Change, 2(1), 20-23.

[25] Jingnan,Shen. (2011). Autonomy in EFL Education. Canadian Social Science, Vol. 7, No. 5, 27-32.

[26] Jordi, Richard. (2011). Reframing the concept reflection: Consciousness, Experiental learning and reflective learning practices. American Association for Adult and Continuing Education. 61(2) 181-197.

[27] Knapp, Michael S.; Copland, Michael A.; \& Talbert, John E. (2003). Leading for learning: Reflective tools for school and district leaders, CTP Research Report. Center for the Study of Teaching and Policy, Seattle, WA.; DeWitt Wallace/Reader's Digest Fund, Pleasantville, NY. 
[28] Kofman, F., \& Senge, P. (1993). Communities of commitment: The heart of the learning organization. Organizational Dynamics, 22(2), 5-23.

[29] Korthagen, F. (1993). Two modes of reflection. Teaching and Teacher Education, 9, 317-326.

[30] McLaughlin, M. W., \& Talbert, J. E. (2001). Professional communities and the work of high school teaching. Chicago: University of Chicago Press.

[31] Milner, H.R. (2003). Teacher reflection and race in cultural contexts: History, meaning, and methods in teaching. Theory into Practice 42, 173-180.

[32] National Association of Elementary School Principals. (2002). Leading learning communities: Standards for what principals should know and be able to do. Alexandria, VA: Author.

[33] National Assessment of Educational Progress. (2004). The nation's report card, 26 August 2004 (accessed 20 September 2011). Available from http://nces.ed.gov/nationsreportcard/.

[34] Ouchi, W. (2003). Making schools work: A revolutionary plan to get your children the education they need. New York: Simon \& Schuster.

[35] Pacheco, A. Quesada. (2005). Reflective teaching and its impact on foreign language teaching. Revista Electrónica “Actualidades Investigativas en Educación” Volumen 5, Número Extraordinario, Año 2005.

[36] Raymond, Margaret E., \& Eric A. Hanushek. (2003). High-Stakes research. Education Next 3,no.3 (Summer):48-55.

[37] Richards, J., \& Lockhart, C. (1994). Reflective teaching in second language classrooms. Cambridge, MA: Cambridge University Press.

[38] Richards, J., \& Rodgers, T. (2001). Approaches and methods in language teaching (2nd ed.). Cambridge, MA: Cambridge University Press.

[39] Seferoğlu, S. S. (2001). Peer coaching: A new approach in professional development of teachers. Education and Science (Eğitim ve Bilim), 26, (119), s. 20-25.

[40] Sergiovanni, T. J. (1996). Leadership for the schoolhouse. San Francisco: Jossey-Bass.

[41] Snipes, J., Doolittle, F., \& Herlihy, C. (2002). Foundations for success: Case studies of how urban school systems improve student achievement. New York: Manpower Development Research Corporation.

[42] Snyder, J. (2002). New Haven Unified School District: A teaching quality system for excellence and equity. In A. M. Hightower, M. S. Knapp, J. A. Marsh, \& M. W. McLaughlin (Eds.), School districts and instructional renewal (pp. 94-110). New York: Teachers College Press.

[43] Southern Regional Education Board. (2003, March). Good principals are the key to successful schools: Six strategies to prepare more good principals. Atlanta, GA: Author.

[44] Stoeckel, P. R., and Davies, T. G. (2007). Reflective leadership by selected community college presidents. Community College Journal of Research and Practice, 31(11), 895-912.

[45] Thomas B. Fordham Institute \& the Broad Foundation. (2003). Better leaders for America's schools: A manifesto. Washington, DC: Author.

[46] Watkins, Paul. (2005). The Principal's role in attracting, retaining, and developing new teachers: Three strategies for collaboration and support. The Clearing House Vol. 79, No. 2 (Nov. - Dec., 2005), pp. 83-87.

[47] Young, D. (1991). Creating a low anxiety classroom environment: What does language anxiety research suggest? Modern Language Journal, 75, 426-439

[48] Zimmerman, Judith. A. (2011). Principals preparing for change: The importance of reflection and professional learning. American Secondary Education 39(2), 107-114.

Suleyman Davut Göker, EdD, is an associate professor of Educational Administration and Supervision and the chair of Department of English Translation and Interpretation, Faculty of Humanities at the Girne American University, North Cyprus. His research focuses on reflective management and supervision and curriculum development in EFL schools. He received his EdD in Educational Administration and Supervision from Dokuz Eylul University, Turkey.

Assoc. Prof. Dr. Suleyman Davut Goker began his career as a director at Diltek English School in Istanbul. He worked as an EFL lecturer at the School of Foreign Languages, Dokuz Eylul University and completed his M.A and Ph.D. in Izmir. He worked as a part-time legal interpreter at the Criminal Courts, Izmir and English examiner of the European Law Students' Association (ELSA) and ISIAC. During his Ph.D study, he has been to Glasgow University as a visiting scholar. He developed an instructional supervision model in ELT for the Ministry of National Education, Turkey. In 1999, he was appointed as an assistant professor of ELT and and director to English Preparatory School, European University of Lefke. He acted as the head and M.A. TEFL coordinator of ELT Department, EUL between 2000 and 2004. In 2002, he went to Bahrain and Jordan as a university representative for a prospective affiliation agreement and the International Education fair. In May 2004, he has been to College of Education, The Ohio State University as a visiting scholar for 5 months and he completed a postdoc research study entitled "The Impact of Peer Coaching on EFL Teachers' Self-efficacy and Instructional Skills". He worked as assistant professor of ELT to the Faculty of Education, Eastern Mediterranean University between September 2004 and September 2006. He was appointed as Associate Professor in July 2008. As of 15 September 2006, he has been acting as head of Department of Translation and Interpreting at GAU. 